\title{
Simulating Study on Drive System Performance for Hybrid Electric Bus Based on ADVISOR
}

\author{
Xingxing Wang, Hongjun Ni , Yu Zhu, Shuaishuai Lv, Mingyu Huang and Zheng Zhang \\ School of Mechanical Engineering, Nantong University, Nantong, 226019, China
}

\begin{abstract}
Hybrid electric bus has a number of advantages when compared with ordinary passenger cars, but in the dynamic matching and the vehicle performance are difficult to detect, thus limits its development process. In this paper, combined with the actual models, the hybrid electric bus module parameters were modified in the software of ADVISOR (Advanced Vehicle Simulator), main including: module of the vehicle, the wheel module, motor module, a battery module and engine module, three kinds of bus models for A, B and C were established, and the related performance that need to be analyzed was set up, such as acceleration, gradability, emissions and energy utilization and so on, in order to ensure the vehicle running in the same environment and convenient for comparison, a fixed vehicle driving cycles was chose, then the simulation results was analyzed, and the various performance was compared with the dynamic indicators and economic indicators which determined by referencing of traditional city bus standard and each other, and finally, the performance optimal model of B was chose out which can meet the demand, its related performance parameters of the simulation results are as follows: the best gradability is $26 \%$, maximum speed is $72.7 \mathrm{~km} / \mathrm{h}$, maximum acceleration is $1.7 \mathrm{~m} / \mathrm{s} 2,0 \sim 50 \mathrm{~km} / \mathrm{h}$ acceleration time is $9.5 \mathrm{~s}$ and fuel consumption is $25 \mathrm{~L} / \mathrm{km}$.
\end{abstract}

\section{Introduction}

Along with the development of the economy, rising energy demand and the increasingly serious environmental problems are not only the two major challenges facing the world today, the sustainable development of the automobile industry is also necessary to overcome the difficulties. Therefore, R\&D personnel related to the development of electric vehicles, hybrid vehicles and fuel cell vehicles [1], [2]. City bus, is one of the urban residents travel tools, can not only use the limited road resources, for people to travel to bring convenience, but also reduce the traffic congestion, resource consumption and air pollution problems, therefore, it is one of the key research object, the application of hybrid technology on city bus is good for the driving condition that complex and changeable characteristics [3]-[5].

ADVISOR software is under the environment of MATLAB/Simulink software development of the advanced vehicle simulation software platform, it can predict, analyze and evaluate the performance, fuel economy and emissions of the vehicle and brake performance. Based on ADVISOR software own hybrid bus models, according to the known parameters of three kinds of hybrid bus model of components, and in particular vehicle driving cycle simulation, according to the simulation results of vehicle fuel economy and acceleration performance analysis, finally get a better comprehensive performance of the models [6]-[8].

\section{The establishment of simulation model}

Hybrid city bus should be level with the same length of the traditional city bus is quite dynamic. Therefore, similar to the design principle of the transmission system and the traditional city buses are judged the maximum speed, climbing ability, the ability to accelerate according to these three indicators. Reference of traditional city bus standard, determine the hybrid electric bus and the dynamic indicators and economic indicators of the following: a top speed of $70 \mathrm{~km} / \mathrm{h}$, or 0 to $50 \mathrm{~km} / \mathrm{h}$ speed up $30 \mathrm{~s}$ or less time, maximum gradability is more than or equal to $20 \%$ [1], [7].

The establishment of simulation model mainly comes with through the model of the software - the secondary development of hybrid electric vehicle (HEV), the object development including: module of the vehicle, the wheel module, motor module, a battery module and engine module. Development method is using MATLAB software to open the corresponding module of the script file, which is called " $\mathrm{m}$ " file. Modifying existing data script file according to the specific data of the target models in the corresponding module [9], [10].

\subsection{Target vehicle parameters}

For identify easily, the three kinds of object models named as $\mathrm{A}, \mathrm{B}$ and $\mathrm{C}$ in this paper, the relevant parameters are listed in the following tables, where the Table 1 for the main parameters of the vehicle model, Table 2 for the main parameters of the engine model, Table 3 for the main 
parameters of the motor model, Table 4 for the main parameters of the battery model.

In addition, the rolling resistance coefficient and air resistance coefficient are 0.013 and 0.6 respectively, which are based on the concrete or asphalt pavement urban road sand vehicle types [11], [12].

Table 1. The main bodywork model parameters of A, B and C.

\begin{tabular}{|c|c|c|c|}
\hline Title & A & B & C \\
\hline Length $(\mathrm{mm})$ & 11980 & 11990 & 12000 \\
\hline Width $(\mathrm{mm})$ & 2540 & 2500 & 2550 \\
\hline Height $(\mathrm{mm})$ & 3180 & 3150 & 3250 \\
\hline Wheel base $(\mathrm{mm})$ & 5980 & 5875 & 6000 \\
\hline Front wheel base $(\mathrm{mm})$ & 2096 & 2096 & 2020 \\
\hline Back wheel base $(\mathrm{mm})$ & 1860 & 1836 & 1860 \\
\hline Windward area $\left(\mathrm{m}^{2}\right)$ & 8.08 & 7.88 & 8.29 \\
\hline Shipping mass $(\mathrm{kg})$ & 12300 & 12500 & 12930 \\
\hline Gross mass $(\mathrm{kg})$ & 17800 & 18000 & 18000 \\
\hline Fuel type & diesel & diesel & diesel \\
\hline
\end{tabular}

Table 2. Engine parameter list.

\begin{tabular}{|c|c|c|c|}
\hline Title & $\mathrm{A}$ & $\mathrm{B}$ & $\mathrm{C}$ \\
\hline Delivery capacity & $6.5 \mathrm{~L}$ & $6.7 \mathrm{~L}$ & $6.5 \mathrm{~L}$ \\
\hline \multirow{2}{*}{ Rated power } & $147 \mathrm{~kW}$ & $136 \mathrm{~kW}$ & $140 \mathrm{~kW}$ \\
& $/ 2500 \mathrm{rpm}$ & $/ 2500 \mathrm{rpm}$ & $/ 2500 \mathrm{rpm}$ \\
\hline Maximum torque & $730 \mathrm{Nm}$ & $700 \mathrm{Nm}$ & $700 \mathrm{Nm}$ \\
& $/ 1400 \mathrm{rpm}$ & $/ 1400 \mathrm{rpm}$ & $/ 1400 \mathrm{rpm}$ \\
\hline Maximum speed & $2500 \mathrm{rpm}$ & $2500 \mathrm{rpm}$ & $2500 \mathrm{rpm}$ \\
\hline
\end{tabular}

Table 3. Motor parameter.

\begin{tabular}{|c|c|c|c|}
\hline Title & A & B & C \\
\hline Model & YHD280M-4 & GHS280M-4 & GHS280M-4 \\
\hline Mass (kg) & 500 & 500 & 500 \\
\hline Voltage (V) & 220 & 275 & 275 \\
\hline Electricity (A) & 280 & 230 & 230 \\
\hline $\begin{array}{c}\text { Rated power } \\
(\mathrm{kW})\end{array}$ & 120 & 155 & 155 \\
\hline $\begin{array}{c}\text { Maximum } \\
\text { torque (N-m) }\end{array}$ & 2200 & 1950 & 1950 \\
\hline
\end{tabular}

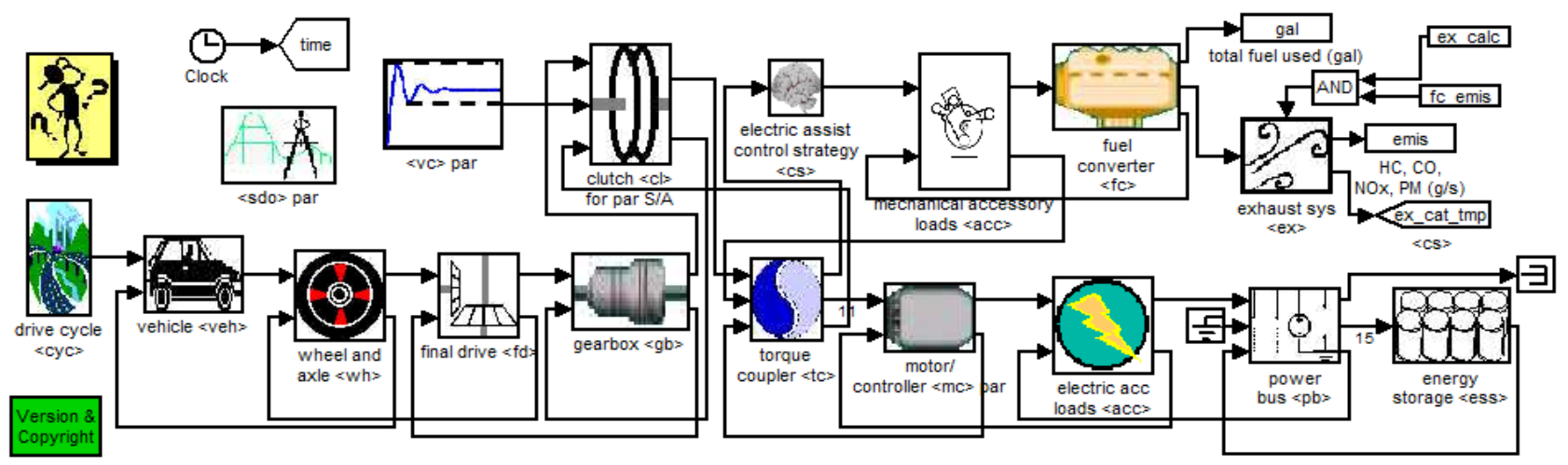

Figure 1. The top model of selected models
Table 4. Battery parameter.

\begin{tabular}{|c|c|c|c|}
\hline Title & A & B & C \\
\hline Voltage (V) & 384 & 384 & 384 \\
\hline Capacity (F) & 41.25 & 41.25 & 41.25 \\
\hline
\end{tabular}

\subsection{Second development of simulation model}

According to the parameters of each mentioned model, modify the vehicle module, the wheel module, the motor module, the battery module and the engine module of the selected software. When using the selected vehicle top model of ADVISOR (Fig. 1), it will automatically call these modified modules. In this way, the simulation model of the target vehicle is established.

\section{Simulation and results discussion}

\subsection{The simulation setup}

Open the ADVISOR, through the vehicle input interface, choose the modified hybrid electric bus model, click the Continue button in the lower-right corner of the window interface, enter the parameters set interface, select condition CYC_CSHVR ( composite driving cycle) as the simulation running road conditions, using the same kind of driving cycle in the process of simulation to facilitate comparing the performance of the three kinds of models, through checking the constant road grade option in the parameters set interface to validate vehicle climbing performance, and then set the climbing gradient for $10 \%$, $15 \%, 20 \%, 25 \%, 20 \%$, interval is $5 \%$, in determining the optimal gradability and narrow interval value to $1 \%$, the same method to determine the optimal gradability; for vehicle Acceleration Test, checking Acceleration Test option in the parameters set interface, in the pop-up interface set the shift delay time is $0.2 \mathrm{~s}$, initial battery capacity is 0.7 , the current quality, 0 to $50 \mathrm{~km}$ Acceleration time parameters to Test the performance. The speed, elevation and running time of CYC_CSHVR conditions as shown in Fig. 2. The Acceleration parameter Settings interface as shown in Fig. 3 [13]-[16]. 


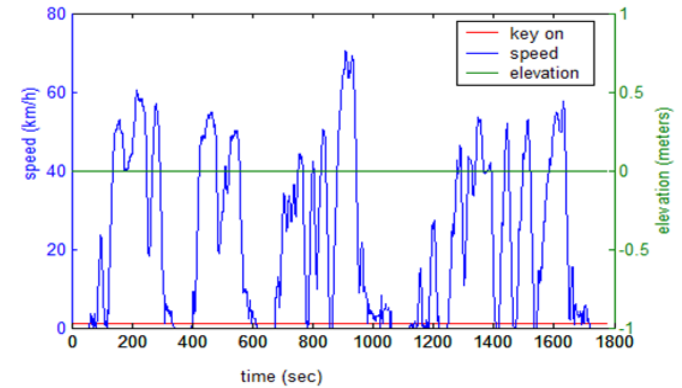

Figure 2. Parameters of CYC_CSHVR

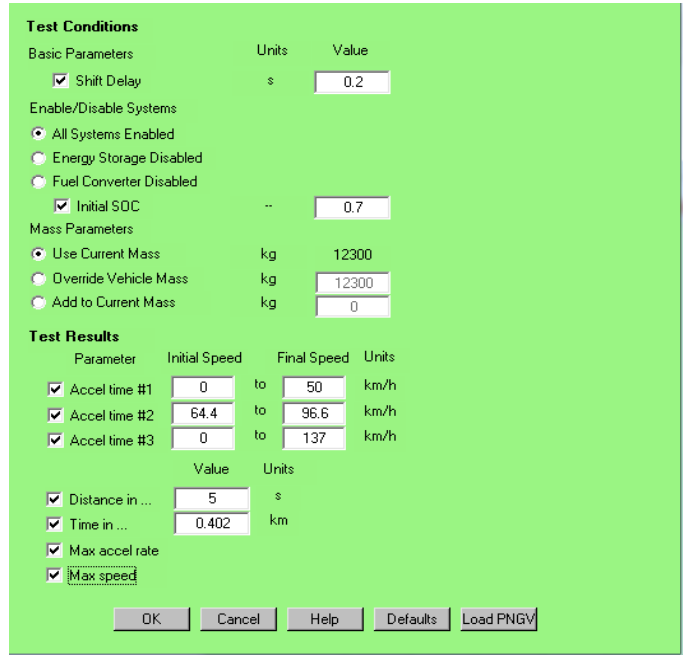

Figure 3. Acceleration parameter settings interface

\subsection{The results of simulation}

Simulated under CYC_CSHVR conditions, than got A, B and $\mathrm{C}$ three kinds of car models of operation conditions. The speed and storage battery charged state relationship with time as shown in Fig. 4, the Fig. 4(a), (b) and (c) respectively corresponding to the three kinds of bus models for A, B and C. From the Fig. 2 and Fig. 3 got that: A, B and $C$ three models of the speed is in good condition and can meet the requirements of working condition, battery charged state (SOC) from 0.7 to 0.6 , also in the reasonable scope of charged.

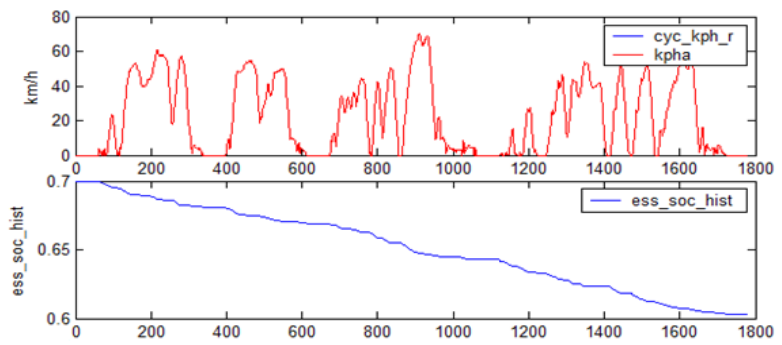

(a) Result of model A

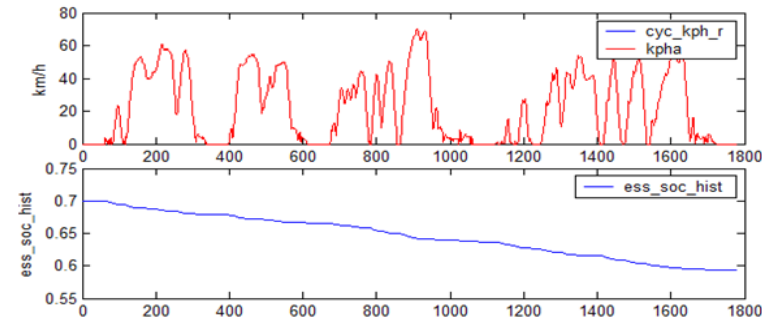

(b) Result of model B

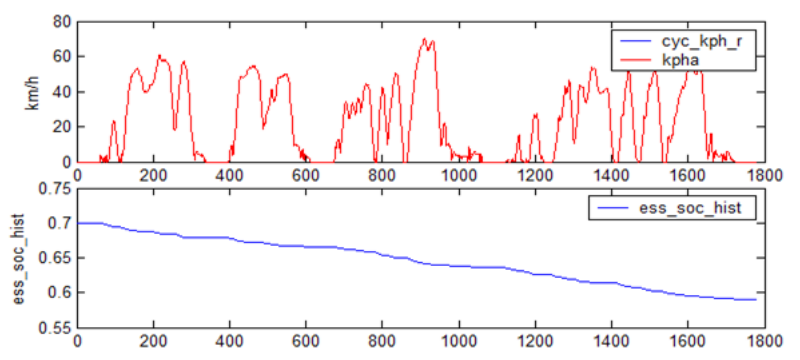

(c) Result of model C

Figure 4. Relationship between speed, battery charged and time

For vehicle climbing performance simulation, it is concluded that the best gradability of A, B and C is $24 \%$, $26 \%$ and $20 \%$.

For fuel consumption rate, acceleration, top speed and maximum acceleration of the simulation results are shown in Table 5.

Table 5. Part of the simulation results.

\begin{tabular}{|c|c|c|c|}
\hline Title & A & B & C \\
\hline Fuel consumption $(\mathrm{L} / \mathrm{km})$ & 27.2 & 25 & 25.7 \\
\hline $\begin{array}{c}0 \sim 50 \mathrm{~km} / \mathrm{h} \text { acceleration time } \\
(\mathrm{s})\end{array}$ & 10.6 & 9.5 & 9.2 \\
\hline Maximum speed $(\mathrm{km} / \mathrm{h})$ & 74.5 & 72.7 & 69.8 \\
\hline $\begin{array}{c}\text { Maximum acceleration } \\
(\mathrm{m} / \mathrm{s} 2)\end{array}$ & 1.4 & 1.7 & 1.13 \\
\hline
\end{tabular}

The simulation results of exhaust emission situation as shown in Fig. 5, the Fig. 5(a), (b) and (c) respectively corresponding to the three kinds of bus models for A, B and $\mathrm{C}$, the specific discharge conditions are shown in Table 6.

The motor working characteristic curve as shown in Fig. 6, the Fig. 6(a), (b) and (c) respectively corresponding to the three kinds of bus models for A, B and C.

Simulation about vehicle interior parts, mainly involves the efficiency of energy utilization, details are shown in the Table 7 .

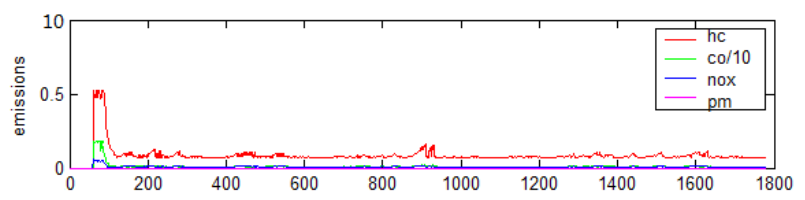

(a) Result of model A

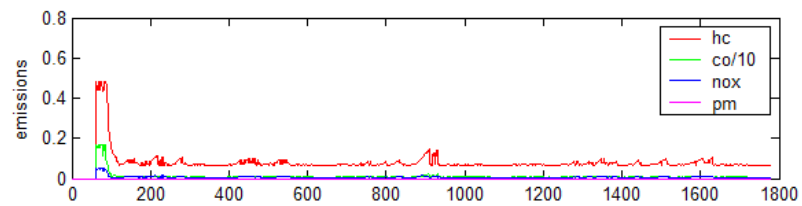

(b) Result of model B

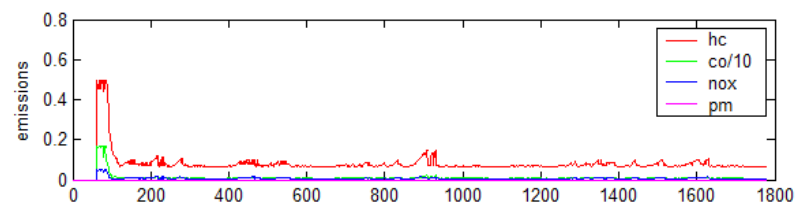

(c) Result of model C

Figure 5. Exhaust emission of $A, B$ and $C$ 


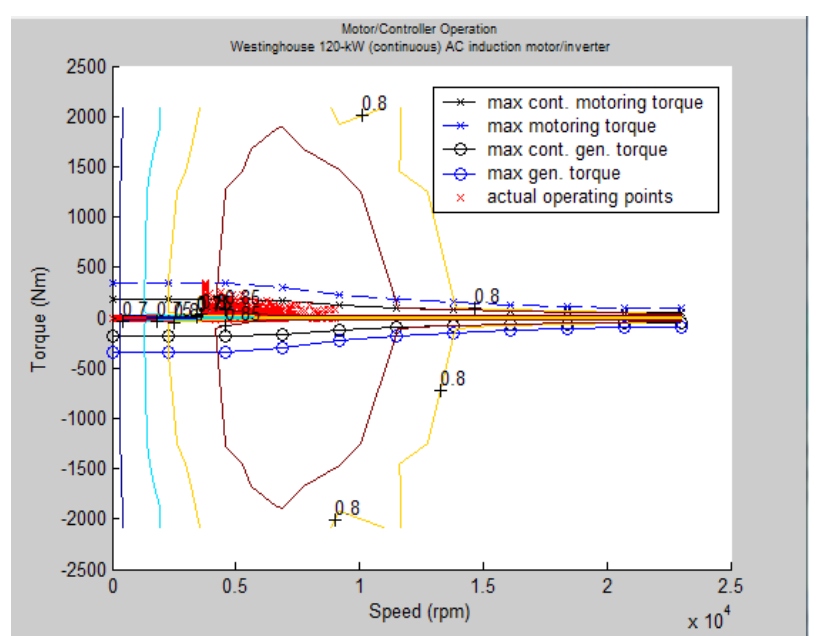

(a) Result of model A

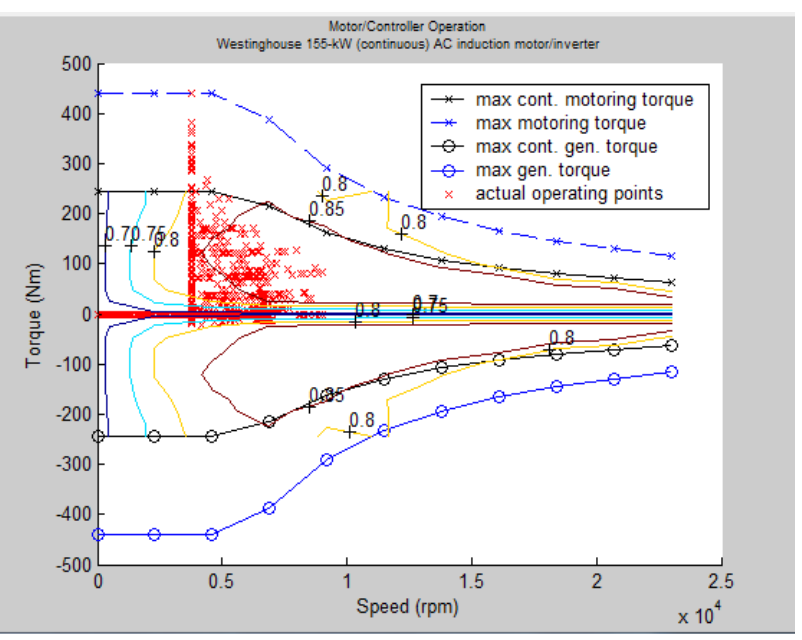

(b) Result of model B

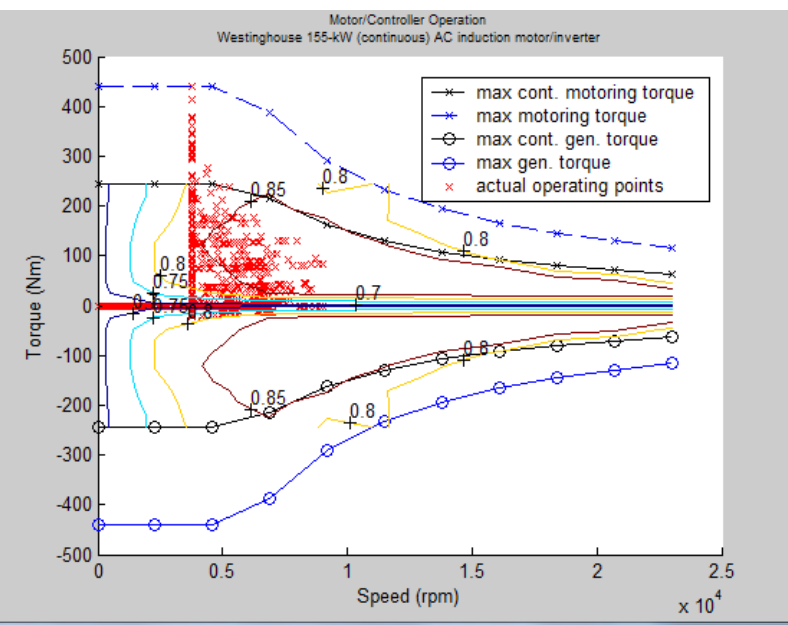

(c) Result of model C

Figure 6. The motor working characteristic curve

Table 6. Exhaust emission.

\begin{tabular}{|c|c|c|c|}
\hline Title & A & B & C \\
\hline $\mathrm{HC}(\mathrm{g} / \mathrm{km})$ & 13.925 & 9.713 & 13.227 \\
\hline $\mathrm{CO}(\mathrm{g} / \mathrm{km})$ & 18.124 & 13.876 & 17.116 \\
\hline $\mathrm{NOX}(\mathrm{g} / \mathrm{km})$ & 1.089 & 0.809 & 1.039 \\
\hline
\end{tabular}

Table 7. The simulation results of energy utilization efficiency.

\begin{tabular}{|c|c|c|c|}
\hline Title & $\mathrm{A}$ & $\mathrm{B}$ & $\mathrm{C}$ \\
\hline Engine & 0.28 & 0.3 & 0.3 \\
\hline Storage battery & 0.68 & 0.88 & 0.88 \\
\hline Electromotor & 0.83 & 0.81 & 0.81 \\
\hline Transmission & 0.95 & 0.95 & 0.95 \\
\hline Wheel & 0.95 & 0.95 & 0.95 \\
\hline
\end{tabular}

\subsection{Contrast and analyze}

Based on speed and battery charged state relationship with time figure and Table 5 shows that A and B models can not only meet the requirements of the driving cycles-the maximum speed and acceleration to the corresponding values, but also achieve the above certain hybrid city bus performance standards, on the contrary, $\mathrm{C}$ bus are not able to meet the two conditions; For A and B models, through the analysis of Table 5: in terms of fuel consumption and accelerate, B is better than A, and in terms of exhaust emissions and energy use efficiency, B is also better than $\mathrm{A}$, the rest of the module are quite similar. Comprehensive the all above aspects of the comparison results, known B more able to meet demand.

\section{Conclusion}

In this paper, on the basis of the original hybrid bus, by modifying the module parameters, three kinds of bus models for A, B and C are established according to the existing models of the simulation model, and through the simulation and analysis, the relatively optimal models of B was determined, the related performance parameters of the simulation results are as follows: the best gradability is $26 \%$, maximum speed is $72.7 \mathrm{~km} / \mathrm{h}$, maximum acceleration is $1.7 \mathrm{~m} / \mathrm{s}^{2}, 0 \sim 50 \mathrm{~km} / \mathrm{h}$ acceleration time is $9.5 \mathrm{~s}$ and fuel consumption is $25 \mathrm{~L} / \mathrm{km}$.

(1) Using the method of modifying parameter on a existing car model in ADVISOR, establish a simulation model, convenient for using of ADVISOR software to develop more models and simulation in subsequent;

(2) Analyzed the vehicle's dynamic performance, energy efficiency, emissions and so on, easy to determine whether the vehicle's power performance meet demand and the energy matching is reasonable and exhaust emission is in line with the standard, for vehicle performance and other aspects of the design and optimization has the guiding effect.

\section{Acknowledgment}

This work is supported by National Science and Technology Support Program of China (2011BAG02B10), A Project Funded by the Priority Academic Program Development of Jiangsu Higher Education Institutions (PAPD), Jiangsu province policy guidance class plan 
(industry university research cooperation) project (BY2015047-02), Frontier and Key Technical Innovation Program of Nantong City (MS22015028).

\section{References}

1. C.J. Yan, J.W. Xia, Y.Y. Cui, Keche Jishu Yu Yanjiu/ Bus \& Coach Technology and Research 36(3), 8 (2014)

2. C. Yang, X.H. Jiao, L. Li, S.X. You, B.J. Yan, Z.L. Ma, Jixie Gongcheng Xuebaol Journal of Mechanical Engineering 51(22), 111 (2015)

3. J.P. Gao, J.Z. Ge, J.B. Zhao, H.B. Qiao, J.G. Xi, Tuxue Xuebao/ Journal of Graphics 35(6), 905 (2014)

4. J. Wang, Q.N. Wang, P.Y. Wang, Proc. Inst. Mech. Eng. Part C J. Mech. Eng. Sci. 229(15), 2760 (2015)

5. T. Ba, Y.H. Gao, Q.N. Wang, X.H. Zeng, Qiche Gongcheng/ Automotive Engineering 37(7), 835 (2015)

6. Y.X. Chen, Q. Ma, X.X. Wang, Zhonguo Keji Lunwen/China Sciencepaper 10(19), 2261 (2015)

7. Y. Sun, L. Li, B.J. Yan, C. Yang, C.Y. Tang, Mech Syst Signal Process 68, 416 (2015)

8. Y.M. Li, F. He, X.S. Jing, L. Yang, Zhizaoye Zidonghual Manufacturing Automation 36(9), 68 (2014)
9. X.S. Hu, J.C. Jiang, B. Egardt, D.P. Cao, IEEE Trans Ind Electron 62(12), 7847 (2015)

10. J. Wang, Q.N. Wang, X.H. Zeng, P.Y. Wang, Proc. Inst. Mech. Eng. Part D J. Automob. Eng. 229(11) 1529 (2015)

11. X.H. Zeng, T. Ba, H. Tian, K. Wu, Q.N. Wang, Jilin Daxue Xuebao (Gongxueban)/Journal of Jilin University (Engineering and Technology Edition) 43(2), 278 (2013)

12. F. Hu, Z.G. Zhao, Z.C. Sun, Qiche Gongcheng/ Automotive Engineering 34(4), 283 (2012)

13. M.L. Dou, C. Shi, Z.L. Chu, G. Wu, Z.J. Ding, S.D. Chen, L.P. Xiong, Y. Hong, J.A. Wang, Kongzhi Gongcheng/Control Engineering of China 19(4), 610 (2012)

14. X.H. Zeng, N.N. Yang, J.N. Wang, D.F. Song, N. Zhang, M.Q. Shang, Mech Syst Signal Process 60-61, $785(2015)$

15. M.Y. Huang, X.B. Feng, D.T. Li, H.J. Ni, X.X. Wang, Nantong Daxue Xuebao(Ziran Kexueban)/Journal of Nantong University (Natural Science Edition) 12(4), $29(2013)$

16. Y. Kim, K. Nam, H. Fujimoto, Y. Hori, Y. Hori, Int. J. Mech. Eng. \& Rob. Res 4(1), 249 (2015) 